05;05.1

\title{
Улучшение пьезоэлектрических свойств ЦТС-керамики в результате низкотемпературного циклирования
}

\author{
(C) П.Н. Якушев ${ }^{1}$, В.В. Шалимов ${ }^{2}$ \\ ${ }^{1}$ Физико-технический институт им. А.Ф. Иофрфе РАН, Санкт-Петербург, Россия \\ ${ }^{2}$ ООО „Силициум“, Санкт-Петербург, Россия \\ E-mail: yak@pav.ioffe.ru
}

Поступило в Редакцию 29 октября 2019г.

В окончательной редакции 29 октября 2019 г.

Принято к публикации 15 ноября 2019 г.

Обнаружено, что в результате низкотемпературного циклирования ЦТС-керамики появляется возможность
улучшить ее пьезоэлектрические свойства. Выяснено, что условия хранения керамики предопределяют
улучшение или ухудшение свойств пьезоматериала после проведения серии высокоградиентных термоударов.

Ключевые слова: пьезоэффект, ЦТС-керамика, пьезоэлементы, термоциклирование.

DOI: 10.21883/PJTF.2020.04.49048.18089

Современный уровень развития техники характеризуется широким и все более возрастающим использованием пьезокерамики в качестве основы для создания элементов электронных устройств. Наиболее изученной и применяемой является пьезокерамика из цирконататитаната свинца - ЦТС-керамика (PZT-ceramics). В настоящей работе описывается разработанная авторами методика, позволяющая улучшать пьезоэффект в ЦТС-керамике. Цель достигается путем проверки с помощью описываемой методики стабильности электрических напряжений, вырабатываемых пьезоэлементом при заданных механических нагрузках и перепадах $100-200$ К в область низких температур.

Объектами исследований были пьезоэлементы из керамики ЦТС-19 толщиной $100 \mu \mathrm{m}$ и диаметром $9 \mathrm{~mm}$, нанесенной на латунный диск (электрод "+") и покрытой тонким слоем серебра (электрод "-"), как показано на рис. 1, $a$. Кольцевой диэлектрический зазор между электродами имеет ширину порядка $0.5 \mathrm{~mm}$. Заряды указанной полярности возникают при сжатии пьезоэлемента. Рис. $1, b$ позволяет различить мелкозернистую структуру керамического покрытия, а также оценить размер зерен, их плотность и равномерность распределения. Пьезоэлементы изготавливались и поляризовались по одной и той же технологии, но хранились в разных условиях: группа $A-$ в морозильной камере при $253 \mathrm{~K}$, группа $B$ - при комнатной температуре (293 K).

Для корректного сравнения напряжений, генерируемых пьезоэлементом при разных температурах, необходимо обеспечить идентичность прикладываемой нагрузки во всех вариантах испытаний. Динамический механический анализатор (ДМА) Exstar 6000 фирмы Seiko был модифицирован специально для этой цели. Задающий нагрузку $F$ верхний электрод гальванически был развязан с ДМА, и измеряемый сигнал через высокоомный интерфейс поступал в компьютер, где и происходили обработка и фиксация сигнала (рис. 2,a). При испытаниях пьезоэлемент устанавливался с прижимом $0.5 \mathrm{~N}$ латунированной стороной на плоское металлическое основание, с которого снимался положительный потенциал, а верхний подвижный электрод (отрицательный потенциал) осуществлял динамическую нагрузку синусоидального вида заданной амплитуды $F$ с частотой $1 \mathrm{~Hz}$ (рис. 2, $a, b)$. Контактная зона подвижного электрода (индентора) в сечении имела вид кольца с внешним диаметром $5 \mathrm{~mm}$ и площадью $7 \mathrm{~mm}^{2}$. Погрешность измерения была не более 5\%. Нагружающее устройство (пьезоэлемент, подвижный и неподвижный электроды) помещалось в рабочую термокамеру ДМА, где задавалась необходимая температура испытаний. В нашем случае температура сначала понижалась до $170 \mathrm{~K}$, а затем ступенчато повышалась до комнатной и выше. Электрическое напряжение с пьезоэлемента (пьезонапряжение) измерялось при установившейся на каждой ступени температуре. После измерения пьезонапряжений исходных образцов групп $A$ и $B$ они подвергались термоциклированию (50 циклов), и измерения повторялись. Один цикл термоциклирования заключался в том, что пьезоэлемент погружался в жидкий азот $(77 \mathrm{~K})$ на $30 \mathrm{~s}$, затем отогревался на воздухе до комнатной температуры. Таким образом, перепад температуры в одном цикле составлял примерно $200 \mathrm{~K}$. Важное методическое значение имеют опыты на пьезоэлементах из групп $A$ и $B$, выполненные при постоянной температуре, но при различных механических давлениях. На рис. 2, $b$ показана для примера характерная для прямого пьезоэффекта пропорциональная зависимость между механическим давлением на пьезокерамику и генерируемым на электродах электрическим напряжением $U$. На вставке к рис. 3 приведены характерные напряжения $U$, которые генерируют пьезоэлементы в серии последовательных нагружений образцов при постоянной температуре. Очевидна стабильная и воспроизводимая работа пьезоэлементов. 


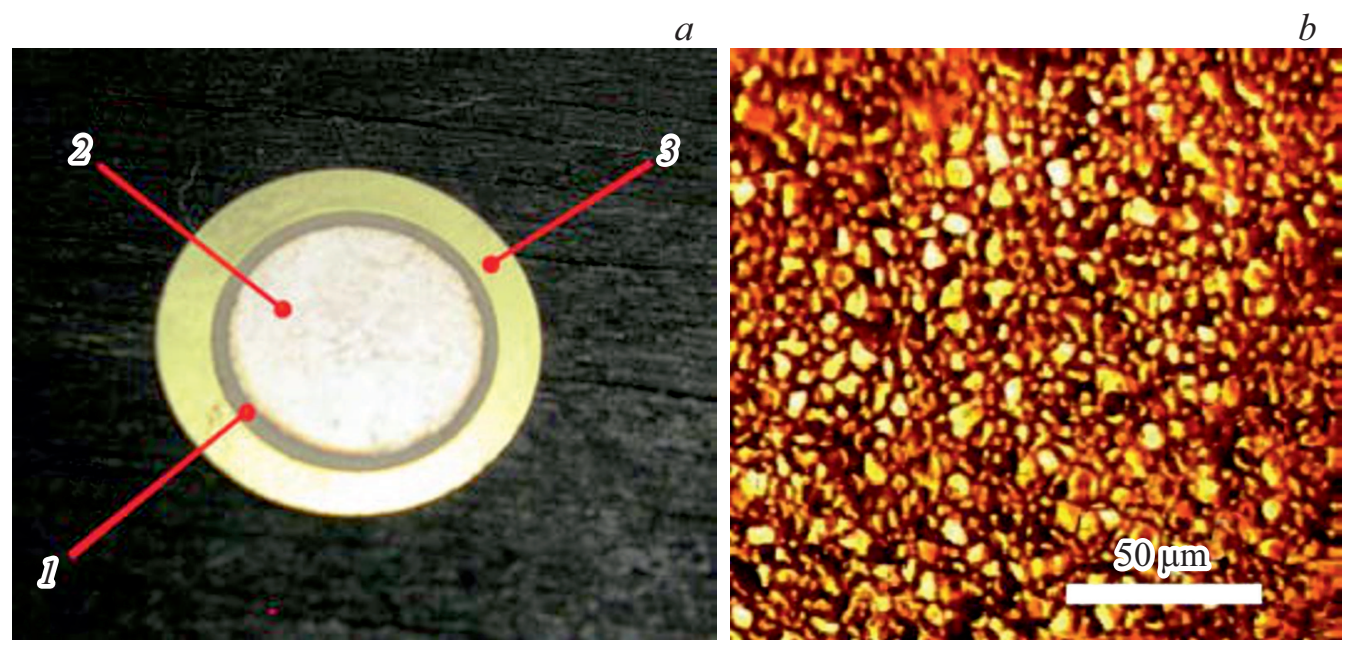

Рис. 1. $a$ - пьезоэлемент. 1 - слой пьезокерамики (диаметр $9 \mathrm{~mm}$, толщина $100 \mu \mathrm{m}), 2$ - электрод „-““ (напыление серебра, диаметр $8 \mathrm{~mm}$, толщина $10 \mu \mathrm{m}), 3$ - электрод „+““ (латунь, диаметр $12 \mathrm{~mm}$, толщина $100 \mu \mathrm{m}) . b$ - микрофотография поверхности пьезокерамики.
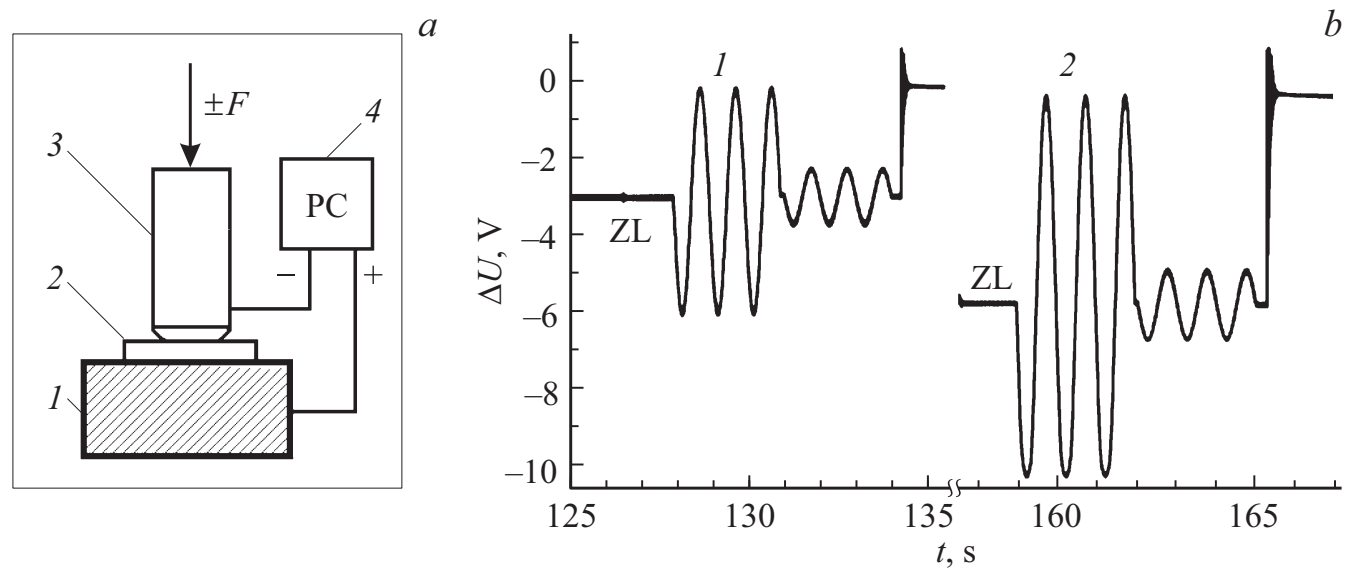

Рис. 2. $a$ - схема нагружающего устройства. 1 - металлическая пластина, $2-$ пьезоэлемент, 3 - кольцевой индентор, $4-$ компьютер. $b$ - изменение электрического пьезонапряжения $U$ при удвоении прикладываемой нагрузки $F$ от $0.5(1)$ до $1 \mathrm{~N}(2)$. $\mathrm{ZL}$ - линия отсчета пьезонапряжения.

На рис. 3 приведена зависимость амплитуды пьезонапряжения $U$ от температуры образца. Во всех случаях к пьезодатчику прикладывалась одинаковая знакопеременная нагрузка $F=0.5 \mathrm{~N}$. Повышение величины сигнала в области низких температур связано, по-видимому, с изменением диэлектрических характеристик при охлаждении образцов и структуры самой керамики. Для оценки степени эволюции пьезоэлектрических свойств целесообразно использовать так называемый коэффициент деградации $K=(u-U) / U$, где $U-$ пьезонапряжение до термоциклирования, а $u$ - после термоциклирования. Коэффициент деградации характеризует изменения в керамике, происходящие после термических воздействий. Положительный $K$ указывает на улучшение пьезоэлектрических свойств. В опытах с исходными образцами обеих групп ( $A$ и $B$ ) мы не обнаружили существенных различий в способности пьезоэлементов генерировать электрическое напряжение. В целом при росте температуры от 173 до $293 \mathrm{~K}$ коэффициент деградации изменяется не более чем на $10 \%$ (рис. 3 ).

В следующей серии экспериментов пьезоэлементы подвергались низкотемпературной циклической обработке. Вначале фиксировалось напряжение $U$ при комнатной температуре. Потом образец помещался в жидкий азот, охлаждался и быстро нагревался на воздухе до комнатной температуры, т.е. проводилась термоциклическая обработка (ТЦО) пьезоэлементов. Число циклов ТЦО равнялось 50. Затем при комнатной температуре и при той же механической нагрузке снова измерялось генерируемое электрическое напряжение $u$. Как правило, оно имело значения, отличные от $U$ (рис. 3). Выяснилось, что ТЦО для образцов из группы $B$ приводит к деградации пьезосвойств. Это выражается в том, что коэффициент деградации $K$ принимает отрицательные 


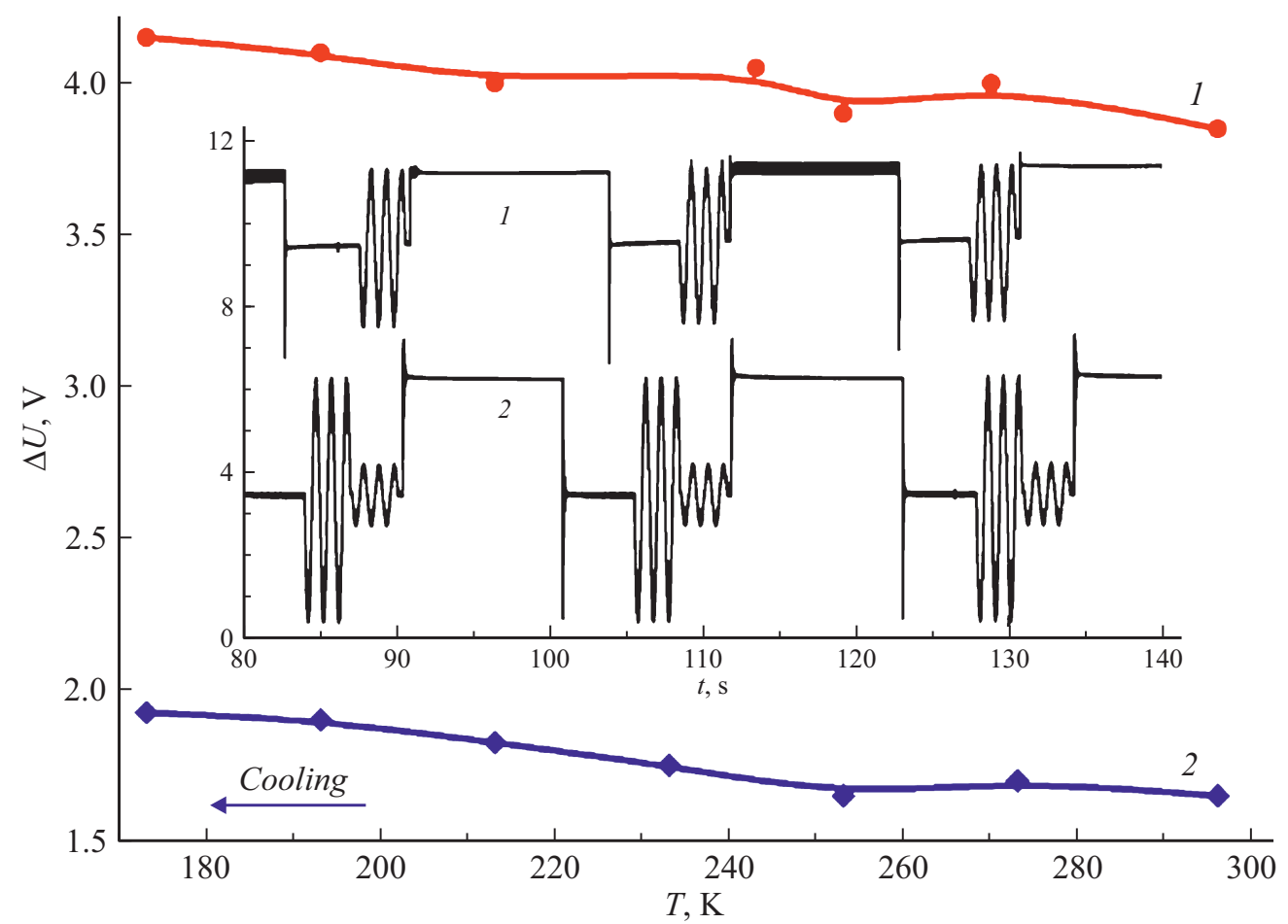

Рис. 3. Зависимость амплитуды пьезонапряжений $U$ и $u$ от температуры для пьезоэлементов группы $B$. На вставке - пример записи напряжений $U$ и $u$ для пьезоэлементов группы $A$ при $293 \mathrm{~K}$. 1 - пьезонапряжение до термоциклирования $(U), 2-$ пьезонапряжение после термоциклирования $(u)$.

значения вплоть до $K=-0.5$, так как напряжение $u$ становится меньше, чем $U$.

Здесь следует отметить, что сами по себе механические воздействия на пьезоэлемент не вызывают деградацию образцов. Для образцов из группы $A$ (хранение в морозильной камере) после серии последовательных охлаждений и нагреваний наблюдается $35 \%$ рост генерируемого при комнатной температуре напряжения $u$ $(K=0.35)$. Оно при многократном нажатии на образец хорошо воспроизводится и стабильно сохраняется длительное время в течение всего периода испытаний. Полученный результат, безусловно, открывает новые перспективы использования пьезокерамики в технике.

В настоящей работе исследовался отклик предельно поляризованной керамики. Взаимодействие доменов по доменной стенке (энергия доменных границ) в ней противостоит действию факторов дезориентации доменов из-за тепла, излучений, остаточных механических напряжений, электрических полей $[1,2]$. В работах [2-4] имеются данные о трансформации доменов под действием различных факторов. В частности, показано, что деградация свойств поляризованной керамики связана с разрушением упорядоченной доменной структуры. Поэтому естественно предположить, что и в нашем случае эволюция электрических свойств керамики тоже связана с перестройкой доменной структуры материала.

В $[5,6]$ изучалась эволюция доменных стенок в процессе быстрого изменения температуры пьезокерамики. Было установлено, что при циклическом охлажде- нии образцов титаната бария (перепад температур 253-293 K) происходит дробление доменов, изменение доменной структуры вплоть до поворота вектора поляризации на 90, появляются сложные субструктуры [7]. В ЦТС-керамиках закалка приводит к искажениям структуры и уменьшению остаточных напряжений. С точки зрения физики пьезоэлемент является слоистым металлокерамическим композитом. В нем при термоударах возникают термомеханические напряжения. Они могут доориентировать часть доменов (тех, которые первоначально не были „заморожены“ в процессе поляризации [2]) в положение, задаваемое электрическим полем при поляризации. Похожие процессы описаны в [8], где было показано, что механические силы могут трансформировать полидоменные формы в монодоменные термодинамически стабильные состояния. В нашем случае аналогичные процессы после проведения ТЦО приводят к росту статической остаточной поляризации в пьезокерамике (группа $A$ ) и заметному улучшению ее пьезоэлектрических свойств.

Таким образом, можно сделать вывод, что использование многократной циклической низкотемпературной обработки позволяет улучшать свойства материалов и получать новые устойчивые структуры. Можно предположить, что эта методика будет эффективна при отработке технологии формирования изделий с улучшенными границами раздела фаз в композитах, высокотемпературных сверхпроводящих керамиках и эпитаксиальных гетероструктурах. 


\section{Конфликт интересов}

Авторы заявляют, что у них нет конфликта интересов.

\section{Список литературы}

[1] Сидоркин А.C. Доменная структура в сегнетоэлектриках и родственных материалах. М.: Физматлит, 2000. 200 с.

[2] Ланин В.Л. Старение пьезокерамики системы ЦТС под действием электрических и механических напряжений. Автореф. канд. дис. Томск: Том. политех. ун-т, 2006. 21 с.

[3] Минчина М.Г., Янковский О.И. // ЖТФ. 1999. Т. 69. В. 6. C. 46- 49 .

[4] Антоненко А.Н., Кудзин А.Ю., Гавшин М.Г. // ФТТ. 1997. T. 39. B. 5. C. $920-921$.

[5] Киселёв Д.А., Ильина Т.С., Малинкович М.Д., Сергеева О.Н., Большакова Н.Н., Семёнова Е.М., Кузнецова Ю.В. // ФТТ. 2018. Т. 60. В. 4. С. 734-738.

[6] Алёшина Л.А., Палатников М.Н., Щербанич Я.И., Феклистова Е.П., Щербина О.Б. // ЖТФ. 2017. Т. 87. В. 3. C. 401-407.

[7] Киселёв Д.А., Афанасьев М.С., Левашов С.А., Чучева Г.В. // ФТT. 2015. Т. 57. В. 6. С. 1134-1137.

[8] Мазур О.Ю., Стефанович Л.И., Юрченко В.М. // ФТТ. 2015. T. 57. B. 7. C. 1358-1364. 